\title{
CANDID SCIENCE IV
}

Conversations with Famous Physicists 


\section{By the same authors}

Candid Science III: More Conversations with Famous Chemists. Imperial College Press, London, 2003. (IH, edited by $\mathrm{MH}$ )

The Road to Stockholm: Nobel Prizes, Science, and Scientists. Oxford University Press,

Oxford, 2002 (paperback edition 2003). (IH)

Candid Science II: Conversations with Famous Biomedical Scientists. Imperial College Press, London, 2002. (IH, edited by $\mathrm{MH}$ )

Candid Science: Conversations with Famous Chemists. Imperial College Press, London, 2000. (IH, edited by $\mathrm{MH}$ )

In Our Own Image: Personal Symmetry in Discovery. Kluwer/Plenum, New York, 2000.

(IH \& $\mathrm{MH})$

Upptäck Symmetri! (Discover Symmetry!, in Swedish, with M. Hargittai). Natur och Kultur, Stockholm, 1998. (MH \& IH)

Symmetry through the Eyes of a Chemist. Second edition, Plenum, New York, 1995. (IH \& $\mathrm{MH})$

Symmetry: A Unifying Concept. Shelter Publications, Bolinas, CA, 1994. (IH \& MH) The VSEPR Model of Molecular Geometry. Allyn \& Bacon, Boston, 1991. (R.J. Gillespie \& $\mathrm{IH})$

The Structure of Volatile Sulphur Compounds. Akadémiai Kiadó, Budapest, 1985. (IH)

The Molecular Geometries of Coordination Compounds in the Vapour Phase. Akadémiai Kiadó, Budapest, 1977. (IH \& MH)

\section{Edited books}

Strength from Weakness: Structural Consequences of Weak Interactions in Molecules, Supermolecules, and Crystals. Kluwer, Dordrecht, 2002. (A. Domenicano \& IH) Symmetry 2000. Vols. I-II, Portland Press, London, 2002. (IH \& T.C. Laurent)

Advances in Molecular Structure Research. Vols. 1-6. JAI Press, Greenwich, CT, 1995-2000. (MH \& IH)

Combustion Efficiency and Air Quality. Plenum, New York, 1995. (IH \& T. Vidóczy) Spiral Symmetry. World Scientific, Singapore, 1992. (IH \& C.A. Pickover)

Fivefold Symmetry. World Scientific, Singapore, 1992. (IH)

Accurate Molecular Structures. Oxford University Press, Oxford, 1992. (A. Domenicano \& $\mathrm{IH})$

Quasicrystals, Networks, and Molecules of Fivefold Symmetry. VCH, New York, 1990. (IH) Symmetry 2: Unifying Human Understanding. Pergamon Press, Oxford, 1989. (IH) Stereochemical Applications of Gas-Phase Electron Diffraction. Vols. A-B, VCH Publishers,

New York, 1988. (IH \& MH)

Crystal Symmetries, Shubnikov Centennial Papers. Pergamon Press, Oxford, 1988. (IH \& B.K. Vainshtein)

Symmetry: Unifying Human Understanding. Pergamon Press, Oxford, 1986. (IH) Diffraction Studies on Non-Crystalline Substances. Akadémiai Kiadó, Budapest, 1981. (IH \& W.J. Orville-Thomas) 


\title{
CANDID SCIENCE IV
}

Conversations with Famous Physicists

\section{Magdolna Hargittai}

\author{
István Hargittai
}




\section{Published by}

Imperial College Press

57 Shelton Street

Covent Garden

London WC2H 9HE

\section{Distributed by}

World Scientific Publishing Co. Pte. Ltd.

5 Toh Tuck Link, Singapore 596224

USA office: Suite 202, 1060 Main Street, River Edge, NJ 07661

UK office: 57 Shelton Street, Covent Garden, London WC2H 9HE

Magdolna Hargittai

Eötvös University and Hungarian Academy of Sciences

H-1518 Budapest, Pf. 32, Hungary

István Hargittai

Budapest University of Technology and Economics

Eötvös University and Hungarian Academy of Sciences

H-1521 Budapest, Pf. 91, Hungary

\section{British Library Cataloguing-in-Publication Data}

A catalogue record for this book is available from the British Library.

\section{CANDID SCIENCE IV \\ Conversations with Famous Physicists}

Copyright (C) 2004 by Magdolna Hargittai and István Hargittai

All rights reserved. This book, or parts thereof, may not be reproduced in any form or by any means, electronic or mechanical, including photocopying, recording or any information storage and retrieval system now known or to be invented, without written permission from the Publisher.

For photocopying of material in this volume, please pay a copying fee through the Copyright Clearance Center, Inc., 222 Rosewood Drive, Danvers, MA 01923, USA. In this case permission to photocopy is not required from the publisher.

ISBN $1-86094-414-0$

ISBN $\quad 1-86094-416-7$ (pbk)

Printed in Singapore. 


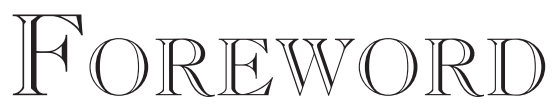

In this volume, some three dozen physicists offer the reader uniquely personal glimpses into their chosen profession, the Physics they inherited, worked in, and are leaving for posterity. What was Physics like in the 20th century? Scientific progress during these past hundred years has given us an extraordinary legacy - a wide-ranging and comprehensive foundation of understanding, powerful tools and techniques with which to refine that understanding, and practical applications which touch upon every significant aspect of modern life, as we know it.

In its early decades, 20th century Physics centered upon the collective efforts of a modest number of European scientists. By mid-century, however, the balance had shifted to a large, and growing, scientific establishment in North America. Enriched by refugees, and enlarged by government support, scientific research in Physics flourished in scope and diversity providing foundations for the nuclear and information revolutions, and catalyzing transformative advances in Astronomy, Biology, Chemistry, and much else besides.

Indeed, so much has happened that we may sometimes forget that all these advances took place within a time scale not much longer than a single human lifetime. This connection with what may seem a far-distant past is reflected in the conversations captured herein - several of which combine first-hand accounts of key advances made as senior researchers, with personal recollections of people and events encountered as students and fledgling scientists. 
Experimental physicists generally gain their clearest insights into Nature's workings by studying phenomena under extreme conditions: energies so high that symmetries break, or so low that quantum condensations occur; the nearly perfect vacuum that Nature was once said to abhor, or the ultra-crowded insides of a neutron star; the mass components of the entire Universe, or the rest mass of a single neutrino. In individual terms, this might mean anything from writing proposals for time on some enormous machine, to crafting, assembling, and adapting bits and pieces in a single laboratory.

If anything, the pathways to theoretical insights range even further, probing spaces its practitioners can only explain to interested outsiders by use of analogies, if at all. Small wonder then, that success stories in this arena usually include years of formal study at a famous University and apprenticeships with distinguished theoreticians. And yet, some seeming outsiders can gain entry, and even join the front rank of contributors. Consider for example, the London-based military attaché who selected a graduate school because of its proximity to his "day job". Without a subject matter expert to guide him, he persisted on his chosen line of research independently rediscovering a series of mistaken conclusions made by earlier workers, before making the discoveries which earned him a place of honor in this select group.

In the end, therefore, the manifest diversity of life experience might seem to thwart attempts at all but the most general categorizations. In place of a rigid roadmap, the compilers of this volume have wisely allowed this diversity to manifest itself in an artfully threaded series of anecdotal excursions - much as a reader might get from a personal conversation with the Hargittais themselves. Accordingly, chronology and sub-disciplines play secondary roles herein, as the thread of conversation moves through one topic and then on to the next. Instead, more subtle groupings become evident as one conversation often serves to introduce the next. Note, for example, that Mößbauer follows Bahcall, reflecting their common involvement in cosmic neutrinos. Similarly, we find microwave background radiation grouped with particle physics, reflecting its relation to cosmic nucleo-synthesis.

Appropriately, the book begins and ends with recollections. The opening conversation centers upon Eugene Wigner's account of people and events in earlier years - a clear link to the past. While superficially similar, David Schoenberg's recollections of Landau and Kapitza serve to turn our attention to the future. In a fitting coda to what has gone before, this final conversation 
serves to reintroduce those of us in the West with our colleagues in the East. Split apart for most of the past century, these two spheres of science once again share in a common community of knowledge - and common hopes for a fruitful future for science and humanity in this new century.

Menlo Park, California, November 2003

Arno Penzias 
This page is intentionally left blank 


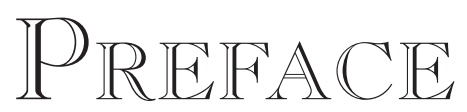

This is the fourth volume of the Candid Science series. It is devoted to famous physicists. Volumes I and III contained interviews with chemists and Volume II with biomedical scientists. Magdolna Hargittai (Magdi, for short) has joined me in authorship for this volume whereas she acted only as Editor for the previous volumes. As it happened, she prepared about half of the interviews in the present volume and I prepared the other half. For a few interviews we acted jointly. Both of us are physical chemists, but she has a special interest in cosmology and in the physics of fundamental particles.

The 36 interviews in this volume present a good, however incomplete, cross section of late 20th century physics. Some of the interviewees were already active and successful physicists in the 1930s. Quite a few participated in the Manhattan Project in various capacities. Whether it was a more prominent role, like Edward Teller or Mark Oliphant, or a less conspicuous one, all who participated in it were impacted by the experience. Some of the interviewees represent a link to such early giants of modern physics as J. J. Thomson, Ernest Rutherford, Niels Bohr, and Enrico Fermi. There is in the volume Laszlo Tisza, whose paper in 1944 was one of the forerunners of the Bose-Einstein Condensation and Wolfgang Ketterle, who was one of its discoverers half a century later. There are Nobel laureates, Wolf laureates, and Templeton laureates in this volume. The number of Nobel laureates is conspicuously high, but the non-laureates are no less great physicists than the laureates. 
We would like to make our collection of interviews yet more comprehensive. Thus, we have not stopped making these interviews and further interviews with physicists will appear in Candid Science $V$.

Our interviews are, in most cases, by-products of our scientific and family travels. When we go to conferences or other trips related to our work, as well as when we are visiting our children, we use the opportunity to record interviews. We both use the same approach to these interviews. We contact our interviewees in advance, set up a date, and record the conversation on audiotape. Back at home we prepare the transcripts and send them for correction and change to the interviewees. This procedure is repeated as many times as it takes until the interviewee is happy with the material. The taping is very informal, providing only a framework for the interview. On the other hand, it is important to have this personal encounter, which could not be substituted by exchanging letters. We never engage anybody else in transcribing our tapes. Listening to them brings back memories of the personal meeting, helps us to capture what was said, and sometimes even gives us clues for a few additional questions that may then be posed in correspondence or at a next meeting. This approach gives a rather tight control of the interviewee over what appears as the text of the interview. However, our experience shows that acting in this way, rather than looking to reveal some "dark secrets", has been helpful in getting closer to our interviewees in a human sense than it might be possible by a more aggressive approach. By the same token, during our actual conversations, some of our questions remain unanswered but then we drop the questions as well from the printed version. In this way the reader may sometimes feel that we should have asked a certain question, and, maybe, we did, but there is no trace of it in what is in this book. We are happy with what we have received without any embarrassment.

The interviews are very different in length and depth. Some interviewees were happy to open up more than others; some were willing to talk in greater detail about their science and about their personal lives than others. Again, we were happy to have what we could get. The circumstances of the recordings were also vastly different. Some interviews were made leisurely in a quiet office or home. Others were squeezed into a crowded program of a scientific meeting or, as it happened, into the rich program of the centennial celebrations of the Nobel Prize in Stockholm.

There is one exception among the 36 interviews communicated in this volume and that is the "interview" with Eugene Wigner. It is not a bona 
fide interview, rather, a summary of a series of conversations I had during Eugene Wigner's visit to the University of Texas at Austin in 1969, while I was a Visiting Research Associate there in the Physics Department. Those conversations stayed deeply ingrained in my mind and I felt there should be an entry from them in this volume augmented by quotations from others.

We note with sadness that three of our interviewees are no longer among us. Eugene Wigner, Mark Oliphant, and Edward Teller have passed away since our interviews with them. I had corresponded with Edward Teller up to a few weeks before his death on September 9, 2003. I am excerpting two letters here as I believe they augment our Teller interview. The original letters were in Hungarian communicated through his assistant, Mrs. Margit Grigory to whom I am grateful for her help in making it possible to keep in touch with the ailing Teller. Here the excerpts from his letters appear in my translation.

\section{From Teller's letter of August 13, 2003:}

In my life's work, I loved science a thousand times more than its applications. I agreed to the latter because I took the dangers of war very much to my heart. I hope you know that I was always against our becoming the first to deploy the hydrogen bomb. I only wanted to have the possibility of the H-bombs as a deterrent for wars, and this has worked so far.

I am convinced that the business of scientists is exclusively science itself. The application of science is the business of politicians and consequently that of the voters. I had problems with my fellow scientists, especially with those according to whom we shouldn't have worked on anything like the hydrogen bomb.

Incidentally, in this question we bitterly differed with Oppenheimer. Similarly we had different positions with Enrico Fermi but with him our friendship did not suffer from this difference. The same can be said about Leo Szilard, who was the most gifted in treading on other peoples' corn, but he never bored anybody.

However, let's though speak about science. Very few performed true science and I knew two such people, Einstein and Bohr. I would be curious to know, what Einstein thought when 
he received the Nobel Prize definitely not for relativity. There are things that are unavoidable, like benzene [reference to the first part of the letter] and the hydrogen bomb, although it may be important for the moment who thought of them first. Things like relativity and quantum mechanics far surpass all other intellectual activities.

For me it is important that the same four letters describe the DNA of all living creatures. This may bring us closer to the understanding of what life is.

From Teller's letter of August 17, 2003 [focusing on the question about success in science]:

Your question is a difficult one, but my answer is easy. I was not an unsuccessful scientist but my scientific research suffered from my work on weapons. Also, in part this happened when I was in the peak of my energies.

In addition, as witnessed by my productive work, I liked to cooperate with others and in this, our disagreement with Oppenheimer caused a lot of damage.

$* * * * *$

We are grateful to the Hungarian Academy of Sciences and the Budapest University of Technology and Economics as well as the Hungarian National Scientific Research Foundation for their support of our research activities in structural chemistry. Our scientific research brings us to meetings and laboratory visits whose byproducts are often the interviews presented here. A very fruitful period was the three months we spent at the Cold Spring Harbor Laboratory at James Watson's invitation in 2002, which gave a convenient opportunity for several interviews. We appreciate Jim and Liz's hospitality and personal attention during our stay there. Our family vacations provide additional opportunities to expand our interviews project.

We also appreciate the dedicated efforts of the associates of Imperial College Press and World Scientific Publishing Company in bringing out this volume. Senior Editor Ms. Ying Oi Chiew spared no labor and attention in making this book as nearly perfect as possible. Her friendly cooperation and pleasant care enhanced our pleasure in working on this project. 
Both Magdi and I are infinitely grateful to all our interviewees for their patience with us and for their fruitful cooperation. We have learned a lot from them in physics, in science history, and in human conduct. Our highest hope is that our readers will similarly benefit from these interviews.

Budapest, October 2003

István Hargittai

\section{Technical Comment}

There is an apparent inconsistency in the way some of the names appear in this volume. However, they were given careful consideration. For example, Peter Kapitsa appears also as Kapitza and his first name as Petr and Pyotr as well. We did not want to arbitrarily change from their original appearances that is the result of difference in transliteration and also in the way he used his name in Cambridge and in Russia. Martinus Veltman's first name also appears as Martin, and Gerardus 't Hooft's first name as Gerard at places. We have consulted about this problem with Drs. Veltman and 't Hooft and we tried our best to follow their preferences. Dr. Tisza's first name appears as László when he is being referred to his time in Hungary. Later, adapting to American usage, his name became Laszlo. 
This page is intentionally left blank 


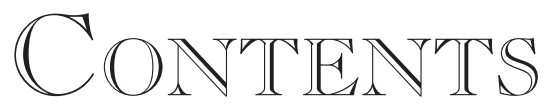

Foreword $\quad$ V

Preface $\quad$ ix

Eugene P. Wigner 2

$\begin{array}{ll}\text { Steven Weinberg } & 20\end{array}$

Yuval Ne'eman $\quad 32$

$\begin{array}{ll}\text { Jerome I. Friedman } & 64\end{array}$

Martinus J. G. Veltman $\quad 80$

$\begin{array}{ll}\text { Gerard 't Hooft } & 110\end{array}$

Leon M. Lederman $\quad 142$

$\begin{array}{ll}\text { Valentine L. Telegdi } & 160\end{array}$

Val L. Fitch 192

$\begin{array}{ll}\text { Maurice Goldhaber } & 214\end{array}$

John N. Bahcall 232

Rudolf Mößbauer $\quad 260$

$\begin{array}{lr}\text { Arno A. Penzias } & 272\end{array}$

$\begin{array}{ll}\text { Robert W. Wilson } & 286\end{array}$ 
xvi Hargittai \& Hargittai, Candid Science

$\begin{array}{lr}\text { Owen Chamberlain } & 298\end{array}$

Marcus L. E. Oliphant 304

Norman F. Ramsey 316

David E. Pritchard 344

Wolfgang Ketterle $\quad 368$

Laszlo Tisza $\quad 390$

Edward Teller $\quad 404$

$\begin{array}{ll}\text { John A. Wheeler } & 424\end{array}$

Freeman J. Dyson 440

$\begin{array}{ll}\text { John C. Polkinghorne } & 478\end{array}$

Benoit B. Mandelbrot 496

Kenneth G. Wilson $\quad 524$

Mildred S. Dresselhaus $\quad 546$

$\begin{array}{lr}\text { Catherine Bréchignac } & 570\end{array}$

Philip W. Anderson 586

$\begin{array}{ll}\text { Zhores I. Alferov } & 602\end{array}$

$\begin{array}{ll}\text { Daniel C. Tsui } & 620\end{array}$

Antony Hewish $\quad 626$

Jocelyn Bell Burnell $\quad 638$

Joseph H. Taylor 656

$\begin{array}{ll}\text { Russell A. Hulse } & 670\end{array}$

David Shoenberg $\quad 688$

Name Index

$\begin{array}{ll}\text { Cumulative Index of Interviewees } & 709\end{array}$ 